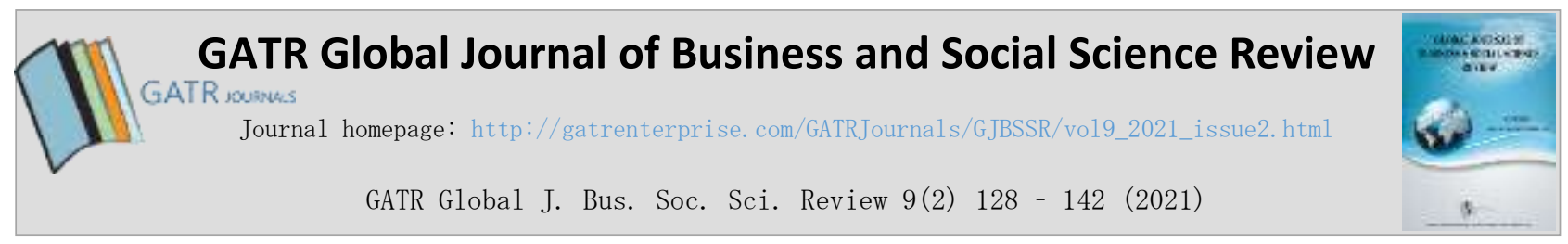

\title{
A Review of the Research on Emergency Logistics for Tropical Cyclone Disasters in Guangxi
}

\author{
Guoyou Yue ${ }^{1 *}$, Boonsub Panichakarn ${ }^{2}$ \\ ${ }^{1,2}$ Faculty of Logistics and Digital Supply Chain, Naresuan University, 99 Moo.9, Thapo, Mueang, 65000, Phitsanulok, \\ Thailand
}

\begin{abstract}
Objective - The purpose of this paper is to find out the key research direction and disaster relief optimization method of governments and organizations at all levels in Guangxi to deal with tropical cyclone disasters.

Methodology/Technique - In terms of research methods, most of the research results focus on the qualitative research of emergency logistics, and the results of quantitative research are relatively few, but there are many kinds of quantitative calculation methods. In terms of focus, the optimization methods of emergency supplies dispatching are studied more, but the forecast results of emergency supplies requirements are less.

Findings - Through literature survey method and in-depth interview method, the research status of emergency logistics is reviewed and analyzed in four aspects: tropical cyclone disaster, basic theory and method of emergency logistics, emergency supplies requirements prediction and emergency supplies dispatching. Through literature combing, there are three main aspects of the discovery. In terms of disaster types, most of the existing research results pay more attention to earthquake, flood and other natural disasters emergency logistics treatment, the results of emergency logistics treatment for tropical cyclone disasters are less, and the results of emergency logistics treatment for tropical cyclone disasters in Guangxi are fewer.

Novelty - By comparing and determining the future research direction of this study, we focus on the formation law of tropical cyclone disaster chain in Guangxi, the optimization treatment methods and practical applications of emergency supplies requirements prediction and emergency supplies dispatching. The research results provide theoretical and methodological guidance for governments and organizations at all levels in Guangxi to carry out tropical cyclone disaster relief, and also point out the research direction and focus for further research in the future.

Type of Paper: Empirical.

JEL Classification: N7, Q54.

Keywords: Emergency Logistics; Tropical Cyclone Disasters; Emergency Supplies Requirements; Emergency Supplies Dispatching; Guangxi

Reference to this paper should be made as follows: Yue, G; Panichakarn, B. (2021). A Review of the Research on Emergency Logistics for Tropical Cyclone Disasters in Guangxi, GATR Global J. Bus. Soc. Sci. Review, 9(2), 128 - 142 https://doi.org/10.35609/gjbssr.2021.9.2(3)
\end{abstract}

\section{Introduction}

Emergency logistics refers to the logistics activities caused by emergencies, including emergency logistics demand generated by emergencies and emergency logistics supply activities to meet these logistics needs, pursuing the purpose of maximizing time efficiency and minimizing disaster losses (Zixue Guo, et al., 2015).

\footnotetext{
* Paper Info: Revised: March 13, 2021

Accepted: June 30, 2021

* Corresponding author: Guoyou Yue

E-mail: 563601374@qq.com

Affiliation: Naresuan University, Thailand
} 
Tropical cyclone is a general term with high central temperature and low pressure formed in tropical ocean atmosphere. Once the system is formed, severe weather phenomena such as strong winds, heavy rain and huge waves occur in a circular range from a few hundred kilometers to dozens of kilometers from the center of the cyclone, which can cause great disasters. Guangxi is affected by many tropical cyclones every year, and serious tropical cyclones cause huge economic losses and casualties throughout Guangxi.

Emergency logistics is a new category of modern logistics, Guangxi and even China's Emergency logistics research started late but developed very quickly. But the research on Emergency logistics related to tropical cyclone disasters is relatively few and has not formed a relatively complete research system. Through collecting domestic and foreign literature on emergency logistics for tropical cyclone disasters, drawing lessons from some developed countries' research achievements and experience in dealing with Emergency logistics for tropical cyclone disasters, this paper strengthens the theoretical research on Emergency logistics for tropical cyclone disasters and pays attention to practical application, so as to form a more perfect Emergency logistics scheme for dealing with tropical cyclone disasters in Guangxi and even China.

Regarding existing studies, a large number of academic research literature related to tropical cyclone disasters and Emergency logistics have been found, in a range of related fields. The rest of the paper is organized as follows. Section 2 summarizes the literature review. Section 3 summarizes the research methodology. Section 4 summarizes the results and discussion. Section 5 is the conclusions to summarize the major problems in existing studies and put forward some suggestions on future research.

\section{Literature review}

There is a large amount of literature on the study of tropical cyclone disasters and emergency logistics, as well as research results on emergency supplies requirements prediction and emergency supplies dispatching models.

\subsection{Natural disasters and disaster management}

There are many kinds of natural disasters. According to the 5200 disasters, the data from 1963 to 1992 , floods, tropical cyclone, droughts, and earthquakes are the most serious types of natural disasters in the world and the focus of disaster reduction (Yuanchang Zheng, 2000). According to the statistics of typhoons that entered the inland of Guangxi from 1970 to 2013, 89 typhoons entered Guangxi in 44 years, with an average of 2 typhoons per year (Jing Li, Liyan Qi, 2015).

Natural disaster management is a complex system of engineering. Disaster management represents activities performed prior, during, and following disasters aimed at minimizing the impact on vulnerable populations and enhancing recovery. Mitigation, preparedness, response, and recovery represent the relevant phases experienced during disaster management (Drabek and Hoetmer, 1991).

Disaster management is an important function of government. The Chinese government has continuously explored in the field of disaster management, formulated the strategy for disaster management of "prevention is the main, disaster prevention, disaster resistance, and disaster relief combined" (Xuejiu Li, 2004). Mexico uses local, regional and national authorities to participate in disaster management. (Oscar Rodríguezespíndola, et al., 2018).

\subsection{Emergency logistics and emergency logistics management}

Emergency logistics is a special logistics activity. The purpose of emergency logistics is to prove needed emergency supplies for sudden natural disasters, sudden public health events, and other sudden events. Its goal is to pursue the maximum benefits of time and minimizing loss of the disaster. emergency logistics, like 
general logistics, is composed of fluid, carrier, flow direction, flow rate, flow path, flow velocity and other elements, and has spatial effects, temporal effects and qualitative effects. In recent years, a series of problems of material delivery and management have been exposed to natural emergencies. Among the huge casualties and property losses caused by sudden natural disasters, the losses caused by inefficient emergency logistics distribution account for about $15 \%$ 20\% of the total losses. For example, the total loss caused by SARS is 17.6 billion us dollars, and the loss caused by emergency logistics is about 3 billion us dollars (Xiaoyan Liu, 2010).

Emergency logistics management system is a complex system. Qi Cheng (2010) put forward the construction of natural disaster emergency logistics management system, including emergency logistics is the integration of classification and grading, staging and coordination management, emergency logistics management system running the risk identification and evaluation, evaluation of emergency logistics management system running ability, the construction of early warning and emergency logistics management system, the construction of emergency logistics public information platform, and the effective measures such as construction of emergency logistics management system. Ping Xia (2010) also put forward the disaster emergency logistics system mainly includes three levels: emergency supplies collection center, emergency supplies distribution center and disaster relief center. Xiaoyan Liu (2010) proposed to establish an organization and command organization of emergency logistics. It is suggested to integrate relevant national military and local organizations and establish a professional emergency logistics command center according to the establishment of Chinese government institutions and logistics operation process. The center is in charge of the overall situation, but it does not directly carry out specific businesses such as material purchase, storage and transportation. It is mainly responsible for guiding the procurement, storage and transportation of materials of each joined logistics center according to the information collected, so as to ensure the efficient and orderly operation of the whole emergency system. A national disaster management and early warning system consisting of six components, namely, National Policy,Legislative and Institutional Environment; National Disaster Management Office (NDMO)- Department of Disaster Prevention and Legislation; Related Ministries/Departments/Institutions; Military/Police; NGOs/IOs/Civil Society; and Current System Capacity that makes up country's disaster management system, was proposed in response to the situation in Thailand (S.H.M. Fakhruddin and Y. Chivakidakarn, 2014).

Emergency logistics management and operation is a complex process. Jinh-Biing Sheu(2010) proposed a dynamic relief demand management model for emergency logistics operations under the condition of incomplete information in large-scale natural disasters. The model mainly includes three steps: predicting the relief needs of multiple regions, classifying the love-affected areas by fuzzy clustering, and ranking the priority of groups by multi-criteria decision making. Flávio E.A. Horita, et al., (2017) proposed an application framework for disaster management in Brazil to connect decisions with data sources through extended modeling symbols and modeling processes. Richard Oloruntoba (2010) identified and analyzed some key success factors in the disaster emergency rescue chain and overall emergency rescue efforts in terms of the impact, physical, social and economic characteristics of Cyclone Larry in Australian.

\subsection{The contents and prediction of emergency supplies requirements}

The type and quantity of emergency supplies requirements depend on the scale, scope, and degree of natural disasters. The emergency supplies requirements refers to the minimum supply requirements for the state to effectively respond to emergencies. Supplies requirements are mainly expressed and measured from two aspects: one is the supplies requirements type, and the other is the supplies requirements quantity. In general, the higher the level of natural disasters, the greater the scope of impact, and the greater the population around the accident, the greater the economic and social losses, and the greater the number of emergency supplies required (Ping Xia, 2010). 
The prediction of emergency supplies requirements is the premise and foundation of emergency supplies dispatching decision, and it is also an effective means to carry out rescue work continuously and effectively. The location, duration, intensity and scope of the tropical cyclone directly affect the emergency supplies requirements. Therefore, it is urgent to use scientific prediction methods to realize the modeling of emergency supplies requirements. Ping Xia (2010) studied the distribution of emergency supplies based on demand analysis in disaster emergency logistics. Proposed based on multiple regression models for predicting the emergency supplies requirements and based on support vector machine models for predicting the emergency supplies requirements, taking the Wenchuan earthquake as an example, whose effectiveness is verified by simulation experiments, provide technical method support for scientific prediction of emergency supplies requirements. Jianming Cai (2011) studied the time-varying and reliability problems of earthquake disaster emergency logistics. The key for the earthquake relief from the disaster area during the period of a number of different relief demand information sources of information chaos and uncertainty puts forward a dynamic relief demand information to identify the reliability of the model. This model is used to estimate the time-varying rescue demand, which is convenient for the dynamic distribution and resource distribution of rescue resources.

\subsection{Solution to vehicle routing problem in emergency supplies dispatching}

There are many ways to solve vehicle routing problem. M. Desrochers et al. (1990) proposed the classification of vehicle routing and scheduling models by four related elements: addresses, vehicles, service strategy, objectives. Ajay K. Rathi et al. (1992) establish a linear programming model to determine the optimal number of vehicles between the origin and destination of the preset route and supply. Luisa Equi et al. (1997) established a model to determine the optimal number of transportation and allocate a reasonable number of trucks between supply and demand points in the supply chain. Rodrigo A. Garrido, et al. (2015) proposed a model to optimize emergency supplies inventory levels and vehicle availability to assist decision makers in dealing with flood emergencies.

There are many ways to solve the transportation route selection problem of emergency logistics. Shaoren Wang (2010) studied location-route problems in post-earthquake emergency logistics system optimization. According to early by air after an earthquake emergency logistics system optimization problem, considering the network interruption, respectively set up by using genetic algorithm always takes at least as the goal of single stage and two-level emergency facilities location-route problems model. Considering the characteristics of post-earthquake emergency logistics system such as timeliness and road network connectivity, an improved genetic algorithm is applied to establish a multi-objective optimization model of fuzzy location-route problems with time window. Thinking of the multi-stage post-earthquake emergency logistics system, multi-level complex networks, such as demand priority features, application of the improved genetic algorithm to establish a multi-stage multi-objective optimization model of a multi-stage fuzzy location-route problems. Jianming Cai (2011) Considered the time variation of travel time and reliability of various sections of transportation network under earthquake disaster environment and combining with the decision weight of decision makers, the analysis and calculation model of transportation route selection for earthquake disaster emergency logistics is presented. Changshi Liu et al. (2016) Considered the problem of emergency facilities, transport capacity constraints, demand point location and terrain in a post-earthquake emergency logistics system, with emergency supplies always arrives in the shortest time with the minimum total distribution costs as the goal, to build a multi-objective fuzzy chance-constrained programming based location-route problems optimization model, and according to the characteristics of the model to design a hybrid immune genetic algorithm to solve. Nariman Nikoo, et al. (2018) proposed three objective functions considering length, travel time and number of paths to determine the optimal network for high-priority emergency travel after earthquakes. 


\subsection{The gap in the above research literature}

The above literature have studied the disasters caused by natural disasters, including tropical cyclones, and put forward some good suggestions on the development of emergency logistics and the establishment of emergency logistics system. At the same time, some emergency supplies requirements prediction methods and emergency supplies dispatching models are put forward. These research results provide a good foundation and reference for the study of this paper, but these research results rarely put forward solutions for the specific situation of tropical cyclone in Guangxi, and lack of research on solving the practical problems of tropical cyclone disasters in Guangxi. The following will strengthen the understanding and research of tropical cyclone disasters in Guangxi through literature survey and in-depth interview method and point out the direction for the follow-up research.

\section{Methodology}

In the process of writing, literature survey and in-depth interview are mainly used.

Through the literature survey, the literature published over the years at home and abroad related to the impact of tropical cyclone disasters, emergency logistics system construction, emergency logistics demand prediction, emergency material scheduling and other aspects were searched to learn the experience and practices of emergency logistics response.

Through the in-depth interview, the author went to the relevant government emergency management departments to learn about the emergency logistics disposal methods for tropical cyclone disasters in Guangxi, including the construction of emergency logistics system in Guangxi, the losses of tropical cyclone disasters over the years in Guangxi, the preparation of emergency materials in Guangxi, and the dispatching mode of emergency materials in Guangxi.

\section{Results and Discussion}

\subsection{Types and investigation results of tropical cyclone disasters in Guangxi}

\subsubsection{Tropical cyclones and classification of tropical cyclone disasters}

According to the notice of China Meteorological Administration on implementing the National Standard of Tropical Cyclone Grade (GB/T 19201-2006), it was officially implemented on June 15, 2006. According to the National Standard of Tropical Cyclone rating, tropical cyclone is divided into six grades, see Table 1

Table 1. Tropical Cyclone Grades.

\begin{tabular}{cccc}
\hline Tropical cyclone grade & Abbreviation & $\begin{array}{c}\text { Maximum wind } \\
\text { speed grade }\end{array}$ & $\begin{array}{c}\text { Central maximum } \\
\text { wind speed }\end{array}$ \\
\hline Tropical Depression & TD & Grade $6-7$ & $10.8 \sim 17.1 \mathrm{~m} / \mathrm{s}$ \\
Tropical Storm & TS & Grade $8-9$ & $17.2 \sim 24.4 \mathrm{~m} / \mathrm{s}$ \\
Severe Tropical Storm & STS & Grade $10-11$ & $24.5 \sim 32.6 \mathrm{~m} / \mathrm{s}$ \\
Typhoon & TY & Grade $12-13$ & $32.7 \mathrm{~m} / \mathrm{s} \sim 41.4 \mathrm{~m} / \mathrm{s}$ \\
Severe Typhoon & STY & Grade $14-15$ & $41.5 \mathrm{~m} / \mathrm{s} \sim 50.9 \mathrm{~m} / \mathrm{s}$ \\
Super Typhoon & Super TY & $\geq$ Grade 16 & $\geq 51.0 \mathrm{~m} / \mathrm{s}$ \\
\hline
\end{tabular}


The meteorological industry-standard Comprehensive Classification of typhoon disaster $(\mathrm{QX} / \mathrm{T} * * * *$ 2009) of the People's Republic of China draws lessons from the grey correlation degree theory, to select the common tropical cyclone disasters indexes that are easy to collect, and through the normalization and dimensionless treatment of each disaster index, the fast evaluation criteria for the comprehensive grade of tropical cyclone disasters in China are established. The number of dead, the number of buildings damaged, the number of crops affected, and the number of direct economic losses are selected as the single statistical index to judge the degree of typhoon disaster. According to every single statistical index, the typhoon disaster is divided into five grades, which are super large, large, medium, small, miniature, and different statistical indexes corresponding to different disaster grades. See Table 2.

Table 2. Standard for single index grade of tropical cyclone disasters.

\begin{tabular}{cccccc}
\hline Index & Super-large & Large & Medium & Small & Miniature \\
\hline $\begin{array}{c}\text { Crop disaster area } \\
\text { (ha.) }\end{array}$ & $(106,+\infty)$ & $(105,106)$ & $(104,105)$ & $(103,104)$ & $(102,103)$ \\
$\begin{array}{c}\text { Dead (people) } \\
\text { Buildings }\end{array}$ & $(102,+\infty)$ & $(30,100)$ & $(10,30)$ & $(3,10)$ & $(1,3)$ \\
$\begin{array}{c}\text { damaged (room) } \\
\text { Direct economic } \\
\text { losses (yuan) }\end{array}$ & $(109,+\infty)$ & $(108,109)$ & $(107,108)$ & $(106,107)$ & $(105,106)$ \\
\hline
\end{tabular}

\subsubsection{Tropical cyclone disasters chain}

The formation of the tropical cyclone disasters chain is the main cause of large-scale serious disasters. Typhoon disasters are mainly caused by the storm, rainstorm, storm surge and the disaster chain caused by the typhoon. The typhoon disaster not only causes a large number of casualties but also has a serious impact on various economic sectors in China. The direct economic losses caused by the typhoon tend to increase year by year. Since the 1990s, the average annual losses have reached more than 10 billion Yuan (Biqi Liang, 1995). According to the sequence of disasters, natural disasters can also be divided into direct disasters, secondary disasters, and derivative disasters (Y. Zhang, W.G. Weng, et al., 2018). See Figure 1 for the tropical cyclone disasters chain. 


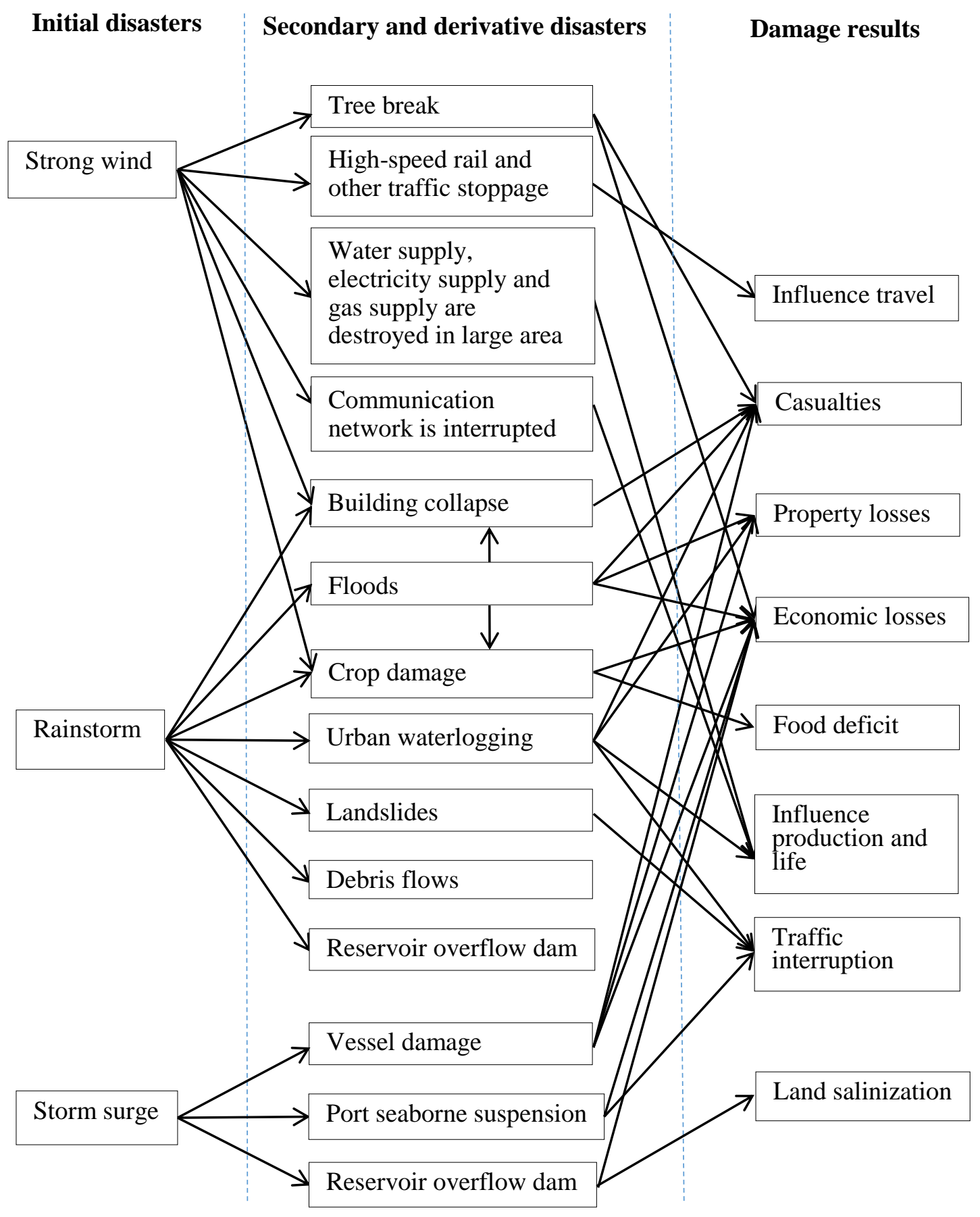

Figure 1. Tropical cyclone disasters chain

\subsubsection{Comprehensive influence of tropical cyclone disasters in Guangxi}

The type of typhoon path into Guangxi and its affected area are different. Huiwen Zhou, et al., (2007) and Jing Li, Liyan Qi, (2015) indicated three types of typhoons entering Guangxi (Class I Path coastal type, Class II Path southeast Guangxi type, and Class III Path northeast Guangxi type, as shown in Figure 2). The results show that the typhoon entering the inland of Guangxi from southeast Guangxi is the most serious, and the 
influence of heavy rainfall is the most serious. The typhoon from the coast to the inland of Guangxi has the most extensive range of disastrous gales, and the frequency of causing super large disasters and large disasters is the highest. However, the typhoon entering the inland of Guangxi from northeast Guangxi is the weakest of the three types of track typhoons, and the disaster caused by the typhoon is usually a medium disaster.

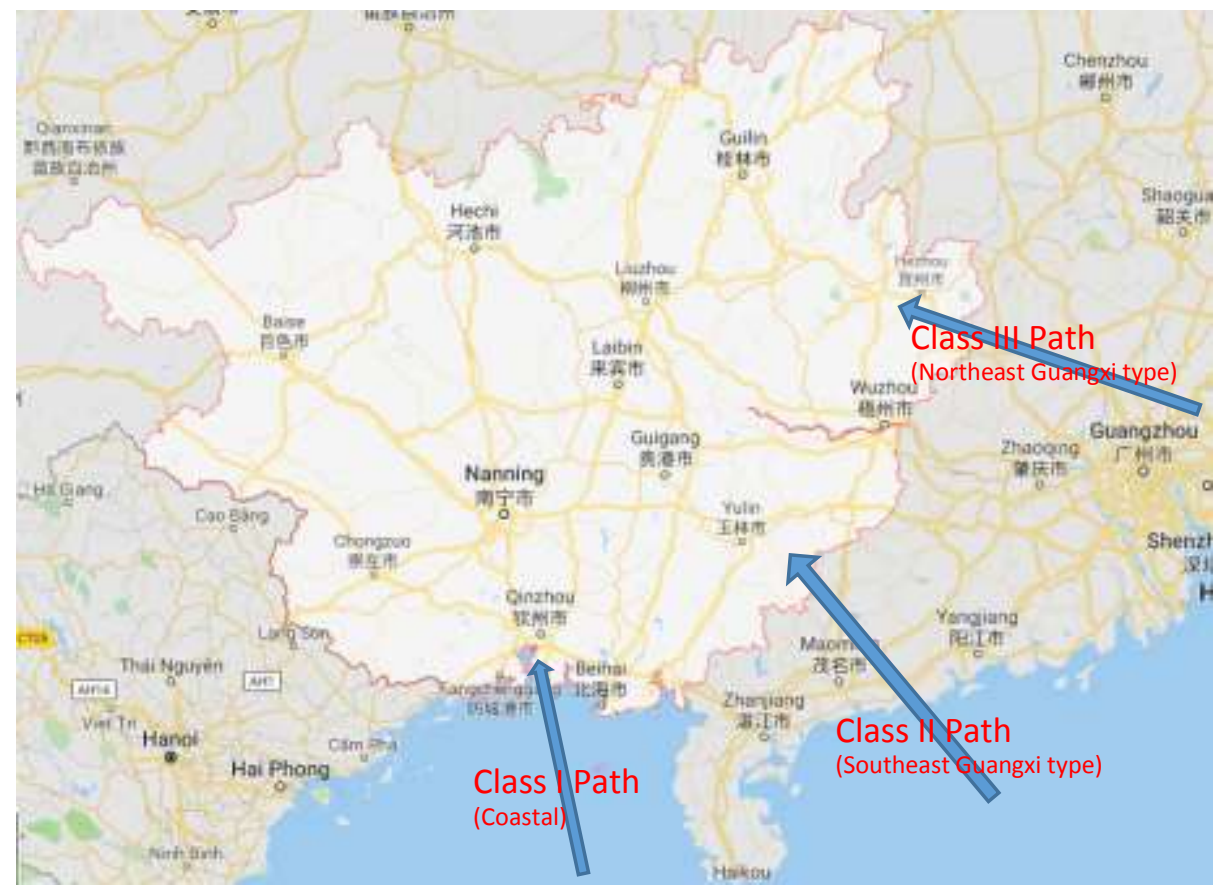

Figure 2. Three tropical cyclone paths into Guangxi

In recent years, Guangxi has also encountered a number of tropical cyclones that cause serious disasters. Such as typhoon No. 0606 "Prapiroon" (Jing Li, et al., 2007), super typhoon No. 1409 "Rammasun" (Changyuan Wang, et al., 2018) and typhoon No. 1621 "Sarika" (Zhuo Huang, Xueping Liao, 2017). Combined with Yearbook of Tropical Cyclone $(2006,2014,2016)$ issued by China Meteorological Administration, the various losses caused by typical tropical cyclone are shown in Table 3.

Table 3. Losses caused by typical tropical cyclone.

\begin{tabular}{ccccccc}
\hline No. & Name & $\begin{array}{c}\text { Number of } \\
\text { Casualties } \\
\text { (people) }\end{array}$ & $\begin{array}{c}\text { Number of } \\
\text { victims(million } \\
\text { people) }\end{array}$ & $\begin{array}{c}\text { Crop disaster area } \\
\text { (million hectares) }\end{array}$ & $\begin{array}{c}\text { Collapsed and } \\
\text { severely damaged economic losses } \\
\text { houses (room) }\end{array}$ & $\begin{array}{c}\text { Direct } \\
\text { (billion yuan) }\end{array}$ \\
\hline 0606 & Prapiroon & 34 & 5.706 & 0.0273 & 11670 & 7.0 \\
1409 & Rammasun & 5 & 4.3211 & 1.456 & 8527 & 13.84 \\
1621 & Sarika & 1 & 0.3521 & 1.776 & 282 & 0.235 \\
\hline
\end{tabular}

\subsection{Build an emergency logistics management system in Guangxi.}

To build an emergency logistics management system is very important in Guangxi. Jingmin Wang and Bowen Sui (2011) according to the location and layout of the emergency logistics base of Guangxi Beibu Gulf Economic Zone put forward as follows: taking Nanning as the emergency logistics center and transportation hub, we can establish "321" core emergency logistics areas, first of all, include three ports of 
Fangchenggang, Qinzhou and Beihai, followed by two major border port cities of Dongxing and Pingxiang, and finally Yulin. Shihong He (2014) put forward Guangxi Beibu Gulf port emergency logistics system is constructed from five aspects: emergency logistics command, emergency logistics operation, emergency logistics information, emergency logistics assistance and emergency logistics resources. The emergency logistics activities of Guangxi Beibu Gulf port, such as emergency supplies purchase, emergency supplies transportation, emergency supplies storage, emergency supplies circulation and processing, emergency supplies distribution and emergency supplies recovery, are explained in detail.

Combined with the above literature and interviews, the emergency logistics management command system model in Guangxi can be built. Show in Figure 3.

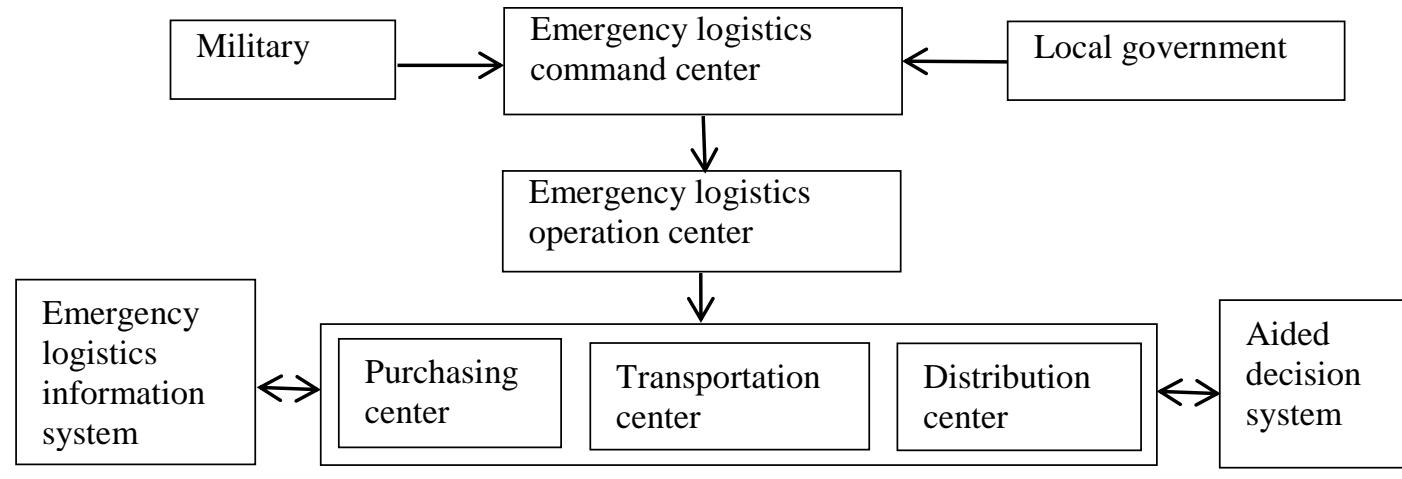

Figure 3. Emergency logistics management command system model

\subsection{The classification and influence factors of emergency supplies requirements for tropical cyclone disasters}

There are many kinds of emergency supplies and different classification methods. Xing Wang (2007) put forward relief supplies are generally divided into three categories: Life-saving equipment, daily necessities, medical devices, and drugs. Ping Xia (2010) put forward the reserve of major disaster relief goods can be divided into 4 major categories. Including living goods, lifesaving items, medical products, heating and cooling goods.

According to the above literature and interview, emergency supplies requirements can be classified as shown in Table 4.

Table 4. Classification of emergency supplies requirements.

\begin{tabular}{cl}
\hline $\begin{array}{c}\text { Supplies } \\
\text { categories }\end{array}$ & \multicolumn{1}{c}{ Major items of emergency supplies requirements } \\
\hline Living goods & $\begin{array}{l}\text { food, drinking water, clean water facilities, grain and oil, lighting equipment, } \\
\text { etc.. } \\
\text { lifeboats, life preserver, life rings, life jackets, exploration instruments, } \\
\text { Lifesaving } \\
\text { items }\end{array}$ \\
$\begin{array}{c}\text { demolition tools, jacking equipment, cranes, etc.. } \\
\text { prodical }\end{array}$ & $\begin{array}{l}\text { medical supplies, first-aid drugs, water purification machinery, and water } \\
\text { purification agents, disinfectant, epidemic prevention drugs, etc.. }\end{array}$ \\
$\begin{array}{c}\text { Heating and } \\
\text { cooling goods }\end{array}$ & quilts, single (cotton) tents, blankets, fuel and fire appliances, cold blankets, etc.. \\
\hline
\end{tabular}


The influence factors of emergency supplies requirements are various. According to the situation of disaster losses, the ministry of civil affairs of the People's Republic of China has set four response levels for natural disasters, with the first, second, third and fourth consecutive decreasing levels. The classification is based on the number of dead, the number of emergency relocation and the number of collapsed houses. As long as one of the indicators is met, the corresponding response level should be activated (Lan Xue, Kaibin Zhong, 2005). Fei Meng, et al. (2007), Fei Zhao, et al. (2011), Jie Yin et al. (2013) and Yanxuan Chen (2017) in order to study the correlation between typhoon disaster situation and disaster source, disaster bearing body, disaster prevention and mitigation. Select the important impact factors including affected population, death toll, crop affected area, collapsed houses, direct economic losses, maximum wind speed to build emergency supplies requirements model and pre-evaluation the disaster level. According to the above literature, the major influencing factors of emergency supplies requirements for tropical cyclone disasters are shown in Table 5.

Table 5. Major influencing factors of emergency supplies requirements for tropical cyclone disasters.

\begin{tabular}{|c|c|}
\hline References & $\begin{array}{l}\text { Major influencing factors of emergency supplies requirements for tropical } \\
\text { cyclone disasters }\end{array}$ \\
\hline $\begin{array}{l}\text { Lan Xue, Kaibin Zhong, } \\
2005\end{array}$ & dead, emergency relocation, collapsed houses. \\
\hline Fei Meng, et al., 2007 & casualties, flooding in the fields, houses collapsed. \\
\hline Fei Zhao, et al., 2011 & $\begin{array}{l}\text { affected population, affected area of crops, direct economic loss rate. } \\
\text { maximum wind speed. }\end{array}$ \\
\hline Jie Yin et al., 2013 & $\begin{array}{l}\text { areas affected by crops, areas not harvested by crops, affected population, } \\
\text { dead population, injured population, emergency resettlement population, } \\
\text { collapsed houses and direct economic losses. }\end{array}$ \\
\hline Yanxuan Chen, 2017 & $\begin{array}{l}\text { affected population, dead population, crop affected area, collapsed houses, } \\
\text { direct economic losses. maximum wind speed. }\end{array}$ \\
\hline
\end{tabular}

\subsection{Models of emergency supplies dispatching for tropical cyclone disasters.}

Emergency supplies dispatching is a complex problem. Linet Özdamar et al. (2004) developed a planning model which addresses the dynamic time-dependent transportation problem that needs to be solved repetitively at given time intervals during ongoing aid delivery. Cheng Miao et al. (2006) analyzed the transportation of many kinds of materials, each kind of goods may have multiple supply points and demand points, the supply and demand of materials, The location of supply and demand will change, vehicles can appear at any point in the supply network, the number is limited and changes with time and so on. Based on the network flow model, the mixed integer programming model of relief material transportation and vehicle scheduling is established. Based on the Lagrangian relaxation method, a drawing transportation scheduling algorithm is designed to solve the approximate optimal solution of the model.

Some authors use multi-objective optimization method to deal with the problem of emergency supplies dispatching. Tirado et al. (2014) use a two-phase flow model to manage the delivery of relief. At the first phase, the difference between the aid planned to be shipped and the aid sent in reality is minimized. At the second phase, to dealt with the time, cost and the highest unsatisfied demand. Liberatore et al. (2014) present a distribution-recovery model for disasters, with the objective of maximizing the total reached demand, minimizing the maximum distance from reliability, security, and demand satisfaction from its ideal value, and minimizing the sum of the attribute distances. Sha-lei Zhang, et al. (2014) incorporate stochastic demands, reliability of the distribution network and Bayesian updates for disaster scenario information. The model proposed minimizes total time, unmet demand, and cost. Oscar Rodríguez-espíndola, at al. (2018) 
contributed to the resource allocation challenge by examining shortages and excess. To design a dynamic optimization model to support relief distribution and resource allocation which incorporates resources from multiple organizations.

\subsection{Discussion}

Through the analysis of the above literature and in-depth interview, earthquakes, tropical cyclone, volcanoes, floods, and other natural disasters occur frequently all over the world, which causes great harm to the life safety and financial losses of people all over the world. Tropical cyclone disasters is a typical representative of all kinds of natural disasters, the frequency is high, the influence range is large, and the harm is also great. Guangxi is also a high incidence area of tropical cyclone disasters, which will suffer from different numbers of tropical cyclone disasters every year, resulting in a large number of people and property losses. In addition to the first strong wind, rainstorm and storm surge disasters, tropical cyclone disasters will also produce a series of secondary and sudden disaster chains, such as floods, mudslides, building collapse, traffic paralysis and so on. Therefore, strengthening the study of the formation law of the tropical cyclone disasters chain has become the research focus and direction of tropical cyclone disasters prevention.

Scholars in various countries have carried out detailed research on the basic concepts, characteristics and management ideas of emergency logistics, and formed a relatively complete theoretical framework of emergency logistics management. Scholars have put forward a lot of effective measures in the construction of the emergency logistics management system, and some scholars have put forward a better plan for Guangxi to build an emergency logistics management system. However, the specific operation of emergency logistics and the research direction of emergency logistics for tropical cyclone need to be further strengthened.

It is shown that the variety of emergency supplies, different natural disasters, the intensity of disasters, the scope of impact, the different affected areas will affect the magnitude of the impact of disasters, and the amount of emergency supplies needed in the affected areas is also very different. Many scholars have put forward a variety of logistics demand prediction methods and application examples. Only a small number of scholars have put forward prediction models for emergency supplies requirements for earthquake disasters, but lack of relevant research results on the emergency supplies requirements for tropical cyclone disasters. Therefore, in the future, combined with the distribution rules of emergency supplies formulated by the emergency management departments of governments at all levels in China, the prediction technology research on emergency supplies requirements for tropical cyclone disasters can be carried out realistically, so as to provide decision-making reference for the emergency management departments at all levels to raise all kinds of emergency supplies.

It is shown that emergency supplies dispatching under the condition of sudden events has always been the focus of emergency logistics research in various countries. In the research process, most of them are carried out under the condition of hypothetical constraints (traffic restrictions, uncertain road environment, etc.) in order to realize the rationalization and efficiency of emergency supplies dispatching, take the optimal combination of vehicle scheduling, the shortest path of transportation, the minimum cost as the research object, take the limited reaction time and limited resources as the research scope, take the multi-objective, the multi-point as the research direction, and use the mathematical method (Linear Programming, Genetic Algorithm, Grey Theory, Bayesian Model, etc.) are established, and a large number of research results are obtained by solving the model through an example study. At present, all kinds of emergency logistics resources in China are still being integrated and perfected, especially there is still a certain gap between Guangxi and developed provinces in emergency logistics management. The above literature focuses on the theory, aiming at the lack of research results on emergency supplies dispatching for tropical cyclone disasters in Guangxi, and there are still many uncertain factors and human decision-making errors in the face of tropical cyclone disasters in real life, so it is necessary to strengthen the practical application research to deal 
with tropical cyclone disasters, which is also the direction and breakthrough point of China emergency supplies dispatching for tropical cyclone disasters, especially in Guangxi.

\section{Conclusions}

To sum up, scholars from all over the world have made a lot of research results on natural disasters and tropical cyclone disasters, the basic theory of emergency logistics, the basic contents and prediction methods of emergency supplies requirements, and the optimization scheme of emergency supplies dispatching. But such studies mainly exist the following three problems.

First, in terms of disaster types, most of the existing research results pay more attention to earthquake, flood and other natural disasters emergency logistics treatment, the results of emergency logistics treatment for tropical cyclone disasters are less, and the results of emergency logistics treatment for tropical cyclone disasters in Guangxi are less. Especially in the emergency supplies requirements prediction and emergency supplies dispatching optimization methods, most of the literature is based on earthquake and flood as an example to carry out verification research. Lack of research results on emergency supplies requirements prediction and emergency supplies dispatching for tropical cyclone disasters.

Second, in terms of research methods, most of the research results focus on the qualitative research of emergency logistics, the results of quantitative research are relatively few, and there are many kinds of quantitative calculation methods. Most of the achievements in tropical cyclone disasters research and emergency logistics research focus on qualitative research. The research results in emergency supplies requirements prediction and emergency supplies dispatching are qualitative and quantitative. Linear Programming, Genetic Algorithm, Grey Theory, Bayesian Model, etc. are specific research methods.

Third, in terms of the key research contents, there are more research on the optimization methods of emergency supplies dispatching, but less results on the prediction of emergency supplies requirements. The specific optimization methods of emergency supplies dispatching include vehicle path selection optimization method, emergency supplies allocation optimization method and so on, and these optimization methods take into account the multi-objective optimization problems such as transportation time and transportation cost. Only a small number of scholars have put forward prediction models for emergency supplies requirements for earthquake disasters, but lack of relevant research results on the emergency supplies requirements for tropical cyclone disasters.

The development and construction of the emergency logistics is a long and arduous process, and the research of the emergency logistics at home and abroad is also in the process of continuous improvement and progress, especially for the emergency logistics method and technology of the tropical cyclone disasters. In the following, some suggestions are put forward on the research and development of the emergency logistics of the tropical cyclone disasters in Guangxi.

First, the research of emergency logistics should pay more attention to practicability and maneuverability and pay attention to integrating theory with practice. In view of the economic and social development of cities and counties vulnerable to tropical cyclone disasters in Guangxi and the construction of emergency system of governments at all levels, the emergency logistics system for tropical cyclone disasters with Guangxi characteristics is constructed.

Second, strengthen the study on the formation factors and effects of tropical cyclone disasters chain. The government should do a good job in preventing primary disasters of tropical cyclone, monitor the prone areas of secondary disasters of tropical cyclone and make good preventive measures to better reduce the human and economic losses caused by disasters.

Third, strengthen the research on the prediction of emergency supplies requirements for tropical cyclone disasters. The classification management of all kinds of emergency supplies is done well, and the corresponding emergency supplies are stored according to the optimized results of demand forecast for long 
time storage. For some emergency supplies which can be purchased directly from the market for a short storage time, the purchaser can be determined, and the corresponding quantity of emergency supplies can be provided to the designated supplier in time when necessary. Through the classified management of all kinds of emergency supplies to reduce the cost of procurement and storage of emergency supplies, to be prepared.

Finally, to strengthen the optimization research of emergency supplies dispatching for tropical cyclone disasters. According to the traffic construction situation of cities and counties vulnerable to tropical cyclone disasters in Guangxi and the location of emergency supplies storage warehouse in cities and counties, an optimization model of emergency supplies dispatching with Guangxi characteristics is established. For Guangxi government emergency departments at all levels to formulate emergency supplies dispatching program to provide reference.

\section{Acknowledgements}

This work is supported by the Financial Support Criteria for Thesis and Oral Presentations Given in National or International Conferences of Graduate Students of the Faculty of Logistics and Digital Supply Chain, Naresuan University. And supported by the "Big Data + Emergency Logistics" team, the second innovation team of Guangxi University of Finance and Economics. And Supported by the Key Disciplines "Management Science and Engineering" Construction Foundation in Guangxi.

\section{References}

Rathi, A. K., Church, R. L., \& Solanki, R. S. (1992). Allocating resources to support a multicommodity flow with time windows. The Logistics and Transportation Review, 28(2), 167-189.

Liang, B., Liang, J., \& Wen, Z. (1995). Study of Typhoon Disasters and Its Effects in China. In Chinese Science Abstracts Series B (Vol. 3, No. 14, pp. 69-70).

Liu, C., Kou, G., Peng, Y., \& Alsaadi, F. E. (2019). Location-routing problem for relief distribution in the early postearthquake stage from the perspective of fairness. Sustainability, 11(12), 3420.

Wang, C., Wu, X., \& Zhou, L. (2018, October). Analysis of Associated Economic Loss of Meteorological Disasters among the Belt and Road Typical Countries__ Taking the China's Typhoon Rammasun in 2014 as an Example. In 8th Annual Meeting of Risk Analysis Council of China Association for Disaster Prevention (RAC 2018) (pp. 198-204). Atlantis Press.

Weisheng, X., \& Qidi, W. (2006). A Transportation Modal and Solution of Large-scale Emergency Relief Commodities. System Engineering, 24(11), 6-12.

Drabek, T. E., \& Hoetmer, G. J. (1991). Emergency Management: Principles and Practice for Local Government. International City Management Association. Municipal Management Series, 141.

Fei, M., Jiancheng, K., Weijiang, L., Tao, W., Tiantian, W., \& Yan, A. (2007). Analysis and Evaluation of Typhoon Disasters In Shanghai in Past 50 Years. Journal of Catastrophology, 4.

Fei Zhao, Yongfeng Liao, Nina Zhang, Yunxia Zhang, Yansiqi Chen. (2011). Research on the model of the preliminary assessment of typhoon damage in China. Disaster science, 26 (2), 81-85. https://doi.org/10.1360/zd-2013-43-6-1064.

Horita, F. E., de Albuquerque, J. P., Marchezini, V., \& Mendiondo, E. M. (2017). Bridging the gap between decisionmaking and emerging big data sources: An application of a model-based framework to disaster management in Brazil. Decision Support Systems, 97, 12-22.

He, G. (2008). Forecast of regional logistics requirements and application of grey prediction model. Journal of Beijing Jiaotong University (Social Sciences Edition), 7(1), 33-37.

Huiwen, Z., Binlian, C., Zaoda, S., \& Liyan, Q. (2007). Characteristics of Disastrous Gale in Guangxi. Journal of Catastrophology, 1.

Cai, J. M., LI, X. M., \& YANG, G. H. (2011). The routing problem for emergency logistics considering the reliability and time-varying in the earthquake disasters. Journal of Railway Science and Engineering, 5.

Jie, Y. I. N., Erfu, D. A. I., Shaohong, W. U., \& Tao, P. A. N. (2013). A study on the relationship between typhoon intensity grade and disaster loss in China. Geographical research, 32(2), 266-274. 
Jing Li, Liyan Qi. (2015). Climatic characteristics of typhoon into interior Guangxi from different paths. Journal of Catastrophology, 30(2), 115-119. https://doi.org/10.13995/j.cnki.11-1802/ts.2014.03.041.

Jing, L., Yijie, W., \& Dongyan, H. (2007). A Contrasting Analysis on the Tropic Cyclone Bilis and Prapiroon. Journal of Catastrophology, 3.

Wang, J. M., \& Sui, B. W. (2011). Research on the Construction of the Emergency Logistics System for Guangxi Beibu Gulf Economic Zone. Logistics Sci-Tech, 08.

Sheu, J. B. (2010). Dynamic relief-demand management for emergency logistics operations under large-scale disasters. Transportation Research Part E: Logistics and Transportation Review, 46(1), 1-17.

Jun-bo, L. I., \& Lina, S. (2011). Demand Forecast of the Cold Chain Logistics Based on the Multiple Linear Regression Analysis. Journal of Anhui Agricultural Sciences, 11.

Xue, L., \& Zhong, K. B. (2005). Classification of types, levels and stages for emergencies: managerial foundation of government emergency response system. Chinese Public Administration, 2.

Lei Huo. (2014). Study on the Forecasting of aquatic Cold Chain Logistics Demand base on Grey-Regression Model (Master's thesis, Beijing Jiaotong University, Beijing, China).

https://kns.cnki.net/kcms/detail/detail.aspx?FileName=1014177520.nh\&DbName=CMFD2014.

Liangjie Wang. (2016). Demand Prediction of Shaanxi’s Fruits Cold Chain Logistics (Master's thesis, Taiyuan University of technology, Taiyuan, China).

https://kns.cnki.net/kcms/detail/detail.aspx?FileName=1016714415.nh\&DbName=CMFD2016.

Vitoriano, B. (2018). Humanitarian Logistics. In Handbook of Disaster Risk Reduction \& Management (pp. 745-772).

Özdamar, L., Ekinci, E., \& Küçükyazici, B. (2004). Emergency logistics planning in natural disasters. Annals of operations research, 129(1), 217-245.

Equi, L., Gallo, G., Marziale, S., \& Weintraub, A. (1997). A combined transportation and scheduling problem. European journal of operational research, 97(1), 94-104.

Desrochers, M., Lenstra, J. K., \& Savelsbergh, M. W. (1990). A classification scheme for vehicle routing and scheduling problems. European Journal of Operational Research, 46(3), 322-332.

Nikoo, N., Babaei, M., \& Mohaymany, A. S. (2018). Emergency transportation network design problem: Identification and evaluation of disaster response routes. International journal of disaster risk reduction, 27, 7-20.

Rodríguez-Espíndola, O., Albores, P., \& Brewster, C. (2018). Decision-making and operations in disasters: challenges and opportunities. International Journal of Operations \& Production Management.

Rodríguez-Espíndola, O., Albores, P., \& Brewster, C. (2018). Dynamic formulation for humanitarian response operations incorporating multiple organisations. International Journal of Production Economics, 204, 83-98.

Ping Xia. (2010). Study of the Emergency supplies Distribution based on the Demand Analysis in Disaster Emergency Logistics (Doctor's thesis, Beijing Jiaotong University, Beijing, China).

https://kns.cnki.net/kcms/detail/detail.aspx?FileName=1011102667.nh\&DbName=CDFD2011.

CHENG, Q., \& YUN, J. (2009). Theoretical Issues About Constructing an Emergency Logistics Management System for Natural Disasters. Journal of Wuhan University of Technology (Social Sciences Edition), 1.

Oloruntoba, R. (2010). An analysis of the Cyclone Larry emergency relief chain: Some key success factors. International Journal of Production Economics, 126(1), 85-101.

Garrido, R. A., Lamas, P., \& Pino, F. J. (2015). A stochastic programming approach for floods emergency logistics. Transportation research part E: logistics and transportation review, 75, 18-31.

Potočnik, P., Šilc, J., \& Papa, G. (2019). A comparison of models for forecasting the residential natural gas demand of an urban area. Energy, 167, 511-522.

Fakhruddin, S. H. M., \& Chivakidakarn, Y. (2014). A case study for early warning and disaster management in Thailand. International journal of disaster risk reduction, 9, 159-180.

Shaoren Wang, Zujun Ma. (2011). Location-routing problem in emergency logistics system for post-earthquake emergency relief response. Systems Engineering — Theory \& Practice, 31(8), 1497-1507.

https://kns.cnki.net/kcms/detail/detail.aspx?FileName=XTLL201108012\&DbName=CJFQ2011

Zhan, S. L., Liu, N., \& Ye, Y. (2014). Coordinating efficiency and equity in disaster relief logistics via information updates. International Journal of Systems Science, 45(8), 1607-1621.

Shihong He. (2014). Research on the construction of Emergency Logistics system of Beibu Gulf Port in Guangxi. Modern economic information, 464. https://doi.org/10.4236/jss.2014.29010. 
Tirado, G., Martín-Campo, F. J., Vitoriano, B., \& Ortuño, M. T. (2014). A lexicographical dynamic flow model for relief operations. International Journal of Computational Intelligence Systems, 7(sup1), 45-57.

Yan, L. X. (2010). China urgent logistic present situation and system construction probing. Special Zone Economy, 2. Xing Wang. (2007). Study of Supplies Distribution Model in Relief Logistics (Master's thesis, Beijing Jiaotong University, Beijing, China).

https://kns.cnki.net/kcms/detail/detail.aspx?FileName=2007084560.nh\&DbName=CMFD2007.

Xueju Li. (2004). Natural disasters and government management in China. Chinese Public Administration, (8), $23-26$. https://doi.org/10.3782/j.issn.1006-0863.2004.08.007.

Yanxuan Chen. (2017). Study on influence factors of Typhoon disaster Preassessment in Guangxi (Master's thesis, Guangxi Teachers Education University, Nanning, China).

https://kns.cnki.net/kcms/detail/detail.aspx?FileName=1017250901.nh\&DbName=CMFD2018.

Yuanchang zheng. (2000). Overview of global natural disasters. Disaster reduction in China, 10 (1), 14-19.

https://kns.cnki.net/kcms/detail/detail.aspx?FileName=ZGJI200001005\&DbName=CJFQ2000.

Zhang, Y., Weng, W. G., \& Huang, Z. L. (2018). A scenario-based model for earthquake emergency management effectiveness evaluation. Technological Forecasting and Social Change, 128, 197-207.

Zhuo Huang, Xueping Liao. (2017). Impact assessment of typhoon "Sarika" on Guangxi in 2016. Journal of meteorological research and application, 38(1), 40-42. https://doi.org/10.3969/j.issn.1673-8411.2017.01.024.

Zixue Guo, Liang Guo, Pei Zhang, Xiaohui Yang. (2015). Time minimization model for emergency material dispatching based on triangle fuzzy information. China Safety Science Journal, 25(10), 172-176. https://doi.org/10.16265/j.cnki.issn1003-3033.2015.10.028. 